\title{
Starch-based completely biodegradable polymer materials
}

\author{
D. R. Lu, C. M. Xiao*, S. J. Xu \\ College of Material Science and Engineering of Huaqiao University, Quanzhou, 362021, P. R. China
}

Received 21 February 2009; accepted in revised form 30 March 2009

\begin{abstract}
Starch is a natural polymer which possesses many unique properties and some shortcoming simultaneously. Some synthetic polymers are biodegradable and can be tailor-made easily. Therefore, by combining the individual advantages of starch and synthetic polymers, starch-based completely biodegradable polymers (SCBP) are potential for applications in biomedical and environmental fields. Therefore it received great attention and was extensively investigated. In this paper, the structure and characteristics of starch and some synthetic degradable polymers are briefly introduced. Then, the recent progress about the preparation of SCBP via physical blending and chemical modification is reviewed and discussed. At last, some examples have been presented to elucidate that SCBP are promising materials for various applications and their development is a good solution for reducing the consumption of petroleum resources and environmental problem.
\end{abstract}

Keyword: biodegradable polymers, starch, biopolymer, preparation, application

\section{Introduction}

As well known, synthetic polymer materials have been widely used in every field of human activity [1] during last decades, i.e. post-Staudinger times. These artificial macromolecular substances are usually originating from petroleum and most of the conventional ones are regarded as non-degradable. However, the petroleum resources are limited and the blooming use of non-biodegradable polymers has caused serious environmental problems. In addition, the non-biodegradable polymers are not suitable for temporary use such as sutures. Thus, the polymer materials which are degradable and/or biodegradable have being paid more and more attention since 1970s.

Both synthetic polymers and natural polymers that contain hydrolytically or enzymatically labile bonds or groups are degradable. The advantages of synthetic polymers are obvious, including predictable properties, batch-to-batch uniformity and can be tailored easily [2]. In spite of this, they are quite expensive. This reminds us to focus on natural polymers, which are inherently biodegradable [3] and can be promising candidates to meet different requirements.

Among the natural polymers, starch is of interest. It is regenerated from carbon dioxide and water by photosynthesis in plants [4]. Owing to its complete biodegradability [5], low cost and renewability [6], starch is considered as a promising candidate for developing sustainable materials. In view of this, starch has been receiving growing attention since 1970s [7, 8]. Many efforts have been exerted to develop starch-based polymers for conserving the petrochemical resources, reducing environmental impact and searching more applications [9-11]. In this paper, the status of preparation and applications of starch-based completely biodegradable (SCBP) polymers is reviewed and presented. 


\section{Structure and properties of starch}

Starch is mainly composed of two homopolymers of D-glucose [8]: amylase, a mostly linear $\alpha$ $\mathrm{D}\left(1,4^{\prime}\right)$-glucan and branched amylopectin, having the same backbone structure as amylose but with many $\alpha-1,6$ '-linked branch points (Figure 1). There are a lot of hydroxyl groups on starch chains, two secondary hydroxyl groups at C-2 and C-3 of each glucose residue, as well as one primary hydroxyl group at C-6 when it is not linked. Evidently, starch is hydrophilic. The available hydroxyl groups on the starch chains potentially exhibit reactivity specific for alcohols. In other words, they can be oxidized and reduced, and may participate in the formation of hydrogen bonds, ethers and esters [12]. Starch has different proportions of amylose and amylopectin ranging from about 10-20\% amylose and $80-90 \%$ amylopectin depending on the source [13]. Amylose is soluble in water and forms a helical structure [14]. Starch occurs naturally as discrete granules since the short branched amylopectin chains are able to form helical structures which crystallize. Starch granules exhibit hydrophilic properties and strong inter-molecular association via hydrogen bonding formed by the hydroxyl groups on the granule surface.

Owing to its hydrophilicity, the internal interaction and morphology of starch will be readily changed by water molecules, and thereby its glass transition temperature $\left(T_{g}\right)$, the dimension and mechanical properties depend on the water content. $T_{g}$ of native starch can be as low as 60 to $80^{\circ} \mathrm{C}$ when the weight fraction of water is in the range 0.12 to 0.14 , which allows starch to be successfully injection moulded to obtain thermoplastic starch polymers in the presence of water [15]. On the other hand, the hydrophilicity of starch can be used to improve the degradation rate of some degradable hydrophobic polymers, which will be shown in 3.1.1.

Starch is totally biodegradable in a wide variety of environments. It can be hydrolyzed into glucose by microorganism or enzymes, and then metabolized into carbon dioxide and water [16]. It is worth noting that carbon dioxide will recycle into starch again by plants and sunshine. Starch itself is poor in processability, also poor in the dimensional stability and mechanical properties for its end products [17]. Therefore, native starch is not used directly.

\section{Preparation of starch-based biodegradable polymers}

To improve the properties of starch, various physical or chemical modifications of starch such as blending, derivation and graft copolymerization have been investigated.
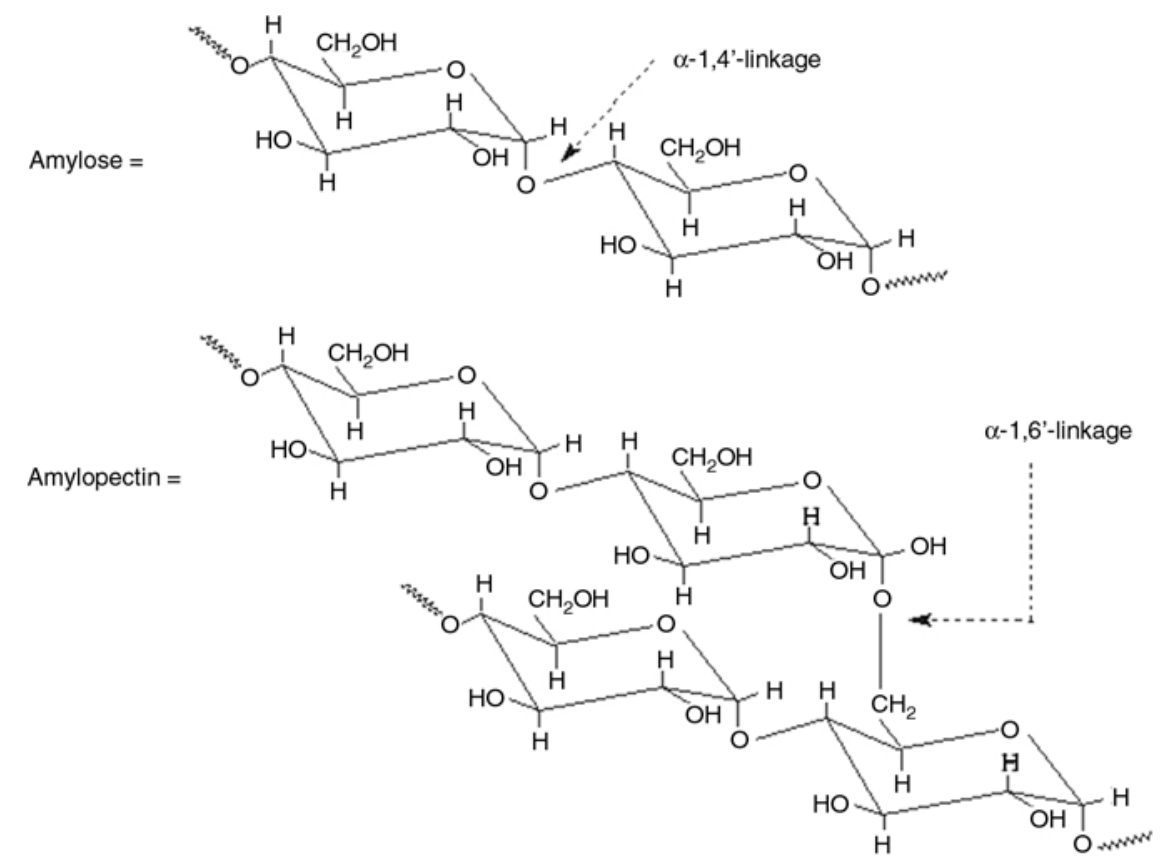

Figure 1. Molecular structure of starch 


\subsection{Physical blends}

\subsubsection{Blend with synthetic degradable polymers}

At first, starch was adopted as a filler of polyolefin by Griffin [18] and its concentrations is as low as $6-15 \%$. Attempts to enhance the biodegradability of the vinyl polymers have been investigated by incorporating starch to a carbon-carbon backbone matrix [19]. In all these cases starch granules were used to increase the surface area available for attack by microorganisms. However, such a system is partially biodegradable and not acceptable from an ecological point of view. Thus, the blends of starch and polyolefin will not be mentioned any more in this article.

To prepare completely biodegradable starch-based composites by this strategy, biodegradable polymers are assumed. Usually, the components to blend with starch are aliphatic polyesters, polyvinyl alcohol (PVA) and biopolymers. The commonly used polyesters are poly( $\beta$-hydroxyalkanoates) (PHA), obtained by microbial synthesis, and polylactide (PLA) or poly( $\varepsilon$-caprolactone) (PCL), derived from chemical polymerization. The goal of blending completely degradable polyester with low cost starch is to improve its cost competitiveness whilst maintaining other properties at an acceptable level [20, 21].

PLA is one of the most important biodegradable polyesters with many excellent properties and has been widely applied in many fields, especially for biomedical one. PLA possesses good biocompatibility and processability, as well as high strength and modulus. However, PLA is very brittle under tension and bend loads and develops serious physical aging during application. Moreover, PLA is a much more expensive material than the common industrial polymers [22].

Many efforts have been made to develop PLA/ starch blends to reduce total raw materials cost and enhance their degradability. The major problem of this blend system is the poor interfacial interaction between hydrophilic starch granules and hydrophobic PLA. Mechanical properties of blends of PLA and starch using conventional processes are very poor because of incompatibility [23]. In order to improve the compatibility between hydrophilic starch granules and hydrophobic PLA, glycerol, formamide, and water are used alone or combined as plasticizers to enhance the dispersion and the interfacial affinity in thermoplastic starch (TPS)/ PLA blends. In the presence of water and other plasticizers including glycerol, sorbitol, urea, and formamide [24], the strong intermolecular and intramolecular hydrogen bonds in starch can be weakened.

To improve the compatibility between PLA and starch, suitable compatibilizer should be added. Besides, gelatinization of starch is also a good method to enhance the interfacial affinity. Starch is gelatinized to disintegrate granules and overcome the strong interaction of starch molecules in the presence of water and other plasticizers, which leads to well dispersion $[25,26]$. The glass transition temperature and mechanical properties of TPS/PLA blend depend on its composition and the content of plasticizer as well (Table 1), indicating the compatibility between PLA and TPS is low but some degree of interaction is formed [26].

PCL is another important member of synthetic biodegradable polymer family. It is linear, hydrophobic, partially crystalline polyester, and can be slowly degraded by microbes [27-29]. Blends between starch and PCL have been well documented in the literatures [30-35]. The weakness of pure starch materials including low resilience, high moisture sensitivity and high shrinkage has been overcome by adding PCL to starch matrix even at low PCL concentration. Blending with PCL, the

Table 1. Thermal and mechanical properties of thermoplastic starch/polylactide (TPS/PLA) blends

\begin{tabular}{|c|c|c|c|c|}
\hline \multirow{2}{*}{$\begin{array}{c}\text { Content of TPS } \\
\text { [wt \%] }\end{array}$} & \multicolumn{2}{|c|}{$\mathbf{T}_{\mathrm{g}}\left[{ }^{\circ} \mathbf{C}\right]$} & \multirow{2}{*}{$\begin{array}{c}\text { Tensile Strength } \\
\text { [MPa] }\end{array}$} & \multirow{2}{*}{$\begin{array}{c}\text { Elongation at Break } \\
{[\%]}\end{array}$} \\
\hline & PLA & TPS & & \\
\hline 100 (TPS1) $^{\mathrm{a}}$ & - & 10 & 3.4 & 152.0 \\
\hline 90 (TPS1) & 47 & $\mathrm{NF}^{b}$ & 2.9 & 48.8 \\
\hline 75 (TPS1) & 53 & $\mathrm{NF}$ & 4.8 & 5.7 \\
\hline $100($ TPS2) & - & 43 & 19.5 & 2.8 \\
\hline 90 (TPS2) & $\mathrm{NF}$ & $\mathrm{NF}$ & 14.1 & 1.3 \\
\hline 75 (TPS2) & $\mathrm{NF}$ & $\mathrm{NF}$ & 12.0 & 0.9 \\
\hline 0 & 58 & - & 68.4 & 9.4 \\
\hline
\end{tabular}

athe content of glycerol and water in TPS1 and TPS2 are 18 and 12,10 and $16 \mathrm{wt} \%$ respectively

${ }^{\mathrm{b}} T_{g}$ value is not found in the literature 
Table 2. Thermal and mechanical properties of thermoplastic starch/polycaprolactone (TPS/PCL) blends

\begin{tabular}{|c|c|c|c|c|}
\hline \multirow{2}{*}{$\begin{array}{c}\text { Content of TPS } \\
\text { [wt\%] }\end{array}$} & \multicolumn{2}{|c|}{$\mathbf{T}_{\mathrm{g}}\left[{ }^{\circ} \mathbf{C}\right]$} & \multirow{2}{*}{$\begin{array}{c}\text { Tensile Strength } \\
{[\mathrm{MPa}]}\end{array}$} & \multirow{2}{*}{$\begin{array}{c}\text { Elongation at Break } \\
{[\%]}\end{array}$} \\
\hline & PCL & TPS & & \\
\hline $100\left(\right.$ TPS1) $^{\mathrm{a}}$ & - & 8.4 & 3.3 & 126.0 \\
\hline 75 (TPS1) & \multicolumn{2}{|c|}{31.0} & 5.9 & 62.6 \\
\hline $100($ TPS2)a & - & 43.4 & 21.4 & 3.8 \\
\hline 75 (TPS2) & \multicolumn{2}{|c|}{41} & 10.5 & 2.0 \\
\hline 60 (TPS2) & \multicolumn{2}{|c|}{$\mathrm{NF}^{\mathrm{b}}$} & 9.0 & 2.4 \\
\hline 0 & -61.5 & - & 14.2 & $>550.0$ \\
\hline
\end{tabular}

athe content of glycerol and water in TPS1 and TPS2 are 18 and 12,10 and 16 wt $\%$ respectively

${ }^{\mathrm{b}} T_{g}$ value is not found in the literature

impact resistance and the dimensional stability of native starch is improved significantly. The glass transition temperature and mechanical properties of TPS/PCL blend are varied with its composition and the content of plasticizer (Table 2) [32]. As can be seen, TPS/PCL blend is similar to TPS/PLA blend in both the compatibility and the role of components.

$\mathrm{PCL} /$ starch blends can be further reinforced with fiber and nano-clay respectively. Moreover, the other properties of the blends such as hydrolytic stability, degradation rate, and compatibilization between PCL and starch are also improved [34, 35]. PVA is a synthetic water-soluble and biodegradable polymer [36]. PVA has excellent mechanical properties and compatibility with starch. PVA/ starch blend is assumed to be biodegradable since both components are biodegradable in various microbial environments. The biodegradability of blends consisting of starch, PVA, glycerol and urea is performed by bacteria and fungi isolated from the activated sludge of a municipal sewage plant and landfill, which indicate that microorganisms consumed starch and the amorphous region of PVA as well as the plasticizers [37]. Meanwhile, the blend is expected to exhibit good mechanical and process properties $[38,39]$. Owing to the strong interaction among hydroxyl groups on PVA and starch chains, all the $T_{g}$ of the starch/PVA blends of different compositions are lower than that of PVA. The excellent compatibility of two components make the tensile strength of the blend increases with increasing PVA concentration, and the elongation at break of the blend is almost kept constant [37]. In addition, PVA can be used to enhance the compatibility of starch/PLA blends. Because both starch and PVA are polyols, starch will form continuous phase with PVA during blending. As a result, the mechanical properties of the starch/PLA blends are improved in the presence of PVA [40]. As for the blend system without PVA, starch acts as filler in the PLA continuous matrix. PLA acts as the main load-bearing phase because of the weak interaction between starch and PLA.

\subsubsection{Blend with biopolymers}

Natural polymers such as chitosan and cellulose and their derivatives are inherently biodegradable, and exhibit unique properties. A number of investigations have been devoted to study the blend of them with starch.

Starch and chitosan are abundant naturally occurring polysaccharide. Both of them are cheap, renewable, non-toxic, and biodegradable [41]. The starch/chitosan blend exhibits good film forming property, which is attributed to the inter- and intramolecular hydrogen bonding that formed between amino groups and hydroxyl groups on the backbone of two components. The mechanical properties, water barrier properties, and miscibility of biodegradable blend films are affected by the ratio of starch and chitosan [42].

Extrusion of the mixture of corn starch and microcrystalline cellulose in the presence or absence of plasticizers (polyols) is used to produce edible films [43]. By increasing the content of the cellulose component, the rupture strength is increased, whereas the elongation at break and the permeability of films for water vapor are decreased. Starch can form thermodynamically compatible blend films with water-soluble carboxymethylcellulose (CMC) when the starch content is below 25 mass\% [44]. Such films are biodegradable in presence of microorganisms.

Starch-based nanocomposite film is obtained by casting the mixture of plasticized starch and flax cellulose nanocrystals. The mechanical properties 
and water resistance are greatly improved. The tensile strength of nanocomposite and unreinforced films are 498.2 and 11.9 MPa respectively [45].

\subsection{Chemical derivatives}

One problem for starch-based blends is that starch and many polymers are non-miscible, which leads to the mechanical properties of the starch/polymer blends generally become poor. Thus, chemical strategies are taken into consideration.

Chemical modifications of starch are generally carried out via the reaction with hydroxyl groups in the starch molecule [46]. The derivatives have physicochemical properties that differ significantly from the parent starch but the biodegradability is still maintained. Consequently, substituting the hydroxyl groups with some groups or chains is an effective means to prepare starch-based materials for various needs.

Graft copolymerization is an often used powerful means to modify the properties of starch. Moreover, starch-g-polymer can be used as an effective compatibilizer for starch-based blends [47-49].

PCL and PLA are chemically bonded onto starch and can be used directly as thermoplastics or compatibilizer. The graft-copolymers starch-g-PCL and starch-g-PLA can be completely biodegraded under natural conditions and exhibit improved mechanical performances. To introduce PCL or PLA segments onto starch, the ring opening graft polymerization of $\varepsilon$-caprolactone or L-lactide with starch is carried out [17, 31, 50, 51].

Starch-g-poly(vinyl alcohol) can be prepared via the radical graft copolymerization of starch with vinyl acetate and then the saponification of the starch-g-poly(vinyl acetate). Starch-g-PVA behaves good properties of both components such as processability, hydrophilicity, biodegradability and gelation ability [52-56].

Starch can be easily transformed into an anionic polysaccharide via chemical functionalization [57]. For instance, a carboxylic derivative of starch, maleic starch half-ester acid (MSA), has been prepared via the esterification of starch with maleic anhydride in the presence of pyridine [58]. MSA is an anionic polyelectrolyte, consequently it can perform ionic self-assembly with chitosan in aqueous solution and forms a polysaccharide-based polyelectrolyte complex [59].

\section{Applications of starch-based biodegradable polymers}

\subsection{In food industry}

Food packaging and edible films are two major applications of the starch-based biodegradable polymers in food industry.

The requirements for food packaging include reducing the food losses, keeping food fresh, enhancing organoleptic characteristics of food such as appearance, odor, and flavor, and providing food safety [60]. Traditional food packaging materials such as LDPE have the problem of environmental pollution and disposal problems [61]. The starchbased biodegradable polymers can be a possible alternative for food packaging to overcome these disadvantages and keep the advantages of traditional packaging materials. However, the components in the conventional starch-based polymer packaging materials are not completely inert. The migration of substances into the food possibly happens, and the component that migrates into food may cause harm for the human body. In view of this, new starch-based packaging materials are being developed. For instance, a starch/clay nanocomposite food packaging material is developed, which can offer better mechanical property and lower migration of polymer and additives [62]. Starch-based edible films are odorless, tasteless, colorless, non-toxic, and biodegradable. They display very low permeability to oxygen at low relative humidity [63] and are proposed for food product protection to improve quality and shelf life without impairing consumer acceptability [64].

In addition, starch can be transformed into a foamed material by using water steam to replace the polystyrene foam as packaging material. It can be pressed into trays or disposable dishes, which are able to dissolve in water and leave a non-toxic solution, then can be consumed by microbic environment [65].

Evidently, the starch-based biodegradable polymers are attractive for food industry and will make great progress in the future.

\subsection{In agriculture}

Starch-based biodegradable polymers have found three major applications in agriculture: the covering of greenhouse, mulch film and fertilizers con- 
trolled release materials [66]. The consumption of agriculture films is abundant. Generally, the disposal methods of tradition films are landfill, recycling or burning. But they are time-consuming, not economic and lead to environmental pollution [67]. On the other hand, the utilization efficiency of fertilizers is the key element of the development of agricultural productions. However, due to surface runoff, leaching and vaporization, the fertilizers escape to environment to cause diseconomy and environmental problems [68, 69].

The development of starch-based biodegradable polymers offers a possibility to overcome the mentioned problems. They can be used as the fertilizers controlled release matrices to release the fertilizers slowly or in controlled way. As a result, the loss of fertilizers and environment pollution can be avoided or reduced $[50,70]$.

After using, starch-based films can be ploughed into soil and disposed directly. Moreover, no toxic residues formed after the degradation of starchbased biodegradable polymers $[71,72]$. Thus, the development of starch-based materials for agriculture applications is being continued. For example, to enhance the mechanical properties and solvent or gas resistance, starch-based biodegradable materials are mixed with some nano-grade additives such as $\mathrm{TiO}_{2}$, layered silicate and MMT to form bionanocomposites [73-75].

\subsection{In medical field}

Starch-based biodegradeable polymers have some advantages to be medical polymer materials [76-81]:
a) good biocompatibility
b) biodegradable and its degradation products are non-toxic
c) proper mechanical properties
d) degradation as requirement

Starch-based biodegradeable polymers have been widely investigated in bone tissue engineering. Starch-based biodegradable bone cements can provide immediate structural support and degrade from the site of application. Moreover, they can be combined with bioactive particles, which allow new bone growth to be induced in both the interface of cement-bone and the volume left by polymer degradation [82]. In addition, starch-based biode-

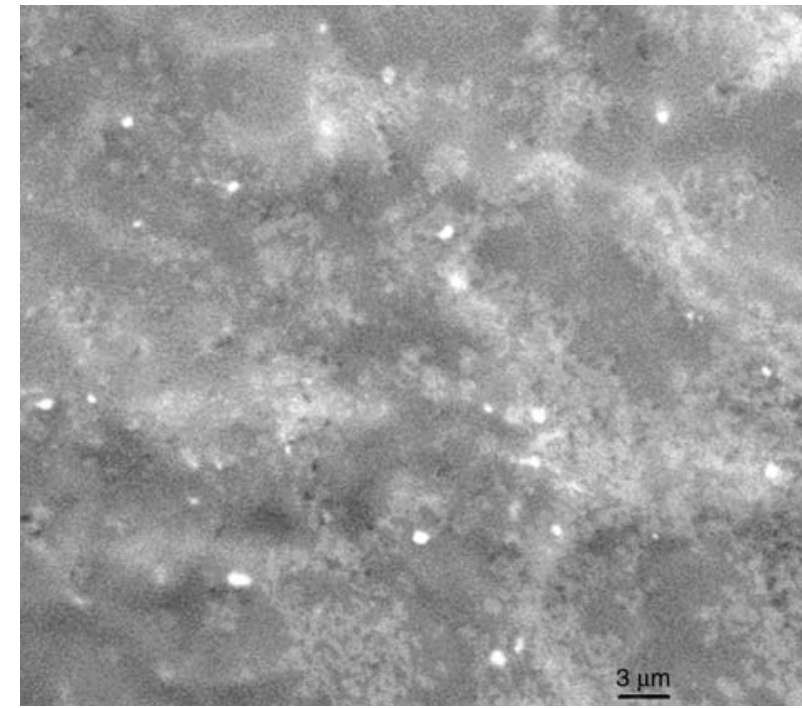

Figure 2. SEM photograph of strach-g-PVA/HA hydrogel (scale bar $3 \mu \mathrm{m}$ )

gradeable polymer can also be used as bone tissue engineering scaffold [83].

Starch-based biodegradable polymers, in the form of microsphere or hydrogel, are suitable for drug delivery [84, 85]. There is no need for surgical removal of the device after drug depletion.

The unique properties, such as hydrophilicity, permeability, biocompatibility, and to some extent similar to soft biological systems, of starch-based hydrogels make them useful for various biomedical applications [86]. The 3D structure of starch-based hydrogels enable them absorb and reserve a plenty of water and keep good enough mechanical property at the same time. Starch-based hydrogels have received growing interest for biomedical applications. In our lab, physically cross-linked starch-gPVA and starch-g-PVA/hydroxyapatite hydrogel are obtained via repeated freezing/thawing circles, and hydroxyapatite (HA) can be well dispersed in such a matrix (Figure 2) [55, 87]. The water content in the fresh starch-g-PVA/HA hydrogel is comparable to that of PVA/HA hydrogel, and the dried starch-g-PVA/HA films can re-adsorb water soon and reach swelling equilibrium within 12 minutes.

\section{Conclusions}

Starch is renewable from carbon dioxide, water and sunshine. It is biodegradable, cheap and to be physical or chemical modified easily. This means someday it is unnecessary to rely on petroleum to 
prepare polymers, people may 'plant' polymers of suitable performances from the earth, and the environmental problems will be no longer as severe as today. At present and in the near future, different physical and chemical approaches are effective strategies to develop starch-based completely biodegradable polymers of appropriate biocompatibility, degradation rate and physical properties for various applications.

\section{References}

[1] Vert M., Santos I. D., Ponsart S., Alauzet N., Morgat J-L., Coudance J., Garreau H.: Degradable polymers in a living environment: Where do you end up? Polymer International, 51, 840-844 (2002).

DOI: $10.1002 / \mathrm{pi} .903$

[2] Nair L. S., Laurencin C. T.: Biodegradable polymers as biomaterials. Progress in Polymer Science, 32, 762-798 (2007).

DOI: $10.1016 /$ j.progpolymsci.2007.05.017

[3] Chiellini E., Solaro R.: Biodegradable polymeric materials. Advanced Materials, 4, 305-313 (1996). DOI: $10.1002 /$ adma.19960080406

[4] Teramoto N., Motoyama T., Yosomiya R., Shibata M.: Synthesis, thermal properties, and biodegradability of propyl-etherified starch. European Polymer Journal, 39, 255-261 (2003). DOI: $10.1016 /$ S0014-3057(02)00199-4

[5] Araújo M. A., Cunha A., Mota M.: Enzymatic degradation of starch-based thermoplastic compounds used in protheses: Identification of the degradation products in solution. Biomaterials, 25, 2687-2693 (2004). DOI: $10.1016 /$ j.biomaterials.2003.09.093

[6] Zhang J-F., Sun X. Z.: Mechanical properties of PLA/starch composites compatibilized by maleic anhydride. Biomacromolecules, 5, 1446-1451 (2004). DOI: $\underline{10.1021 / \mathrm{bm} 0400022}$

[7] Griffin G. J. L.: Starch polymer blends. Polymer Degradation and Stability, 45, 241-247 (1994). DOI: 10.1016/0141-3910(94)90141-4

[8] Pareta R., Edirisinghe M. J.: A novel method for the preparation of starch films and coatings. Carbohydrate Polymer, 63, 425-431 (2006). DOI: $10.1016 /$ j.carbpol.2005.09.018

[9] Park J. S., Yang J. H., Kim D. H., Lee D. H.: Degradability of expanded starch/PVA blends prepared using calcium carbonate as the expanding inhibitor. Journal of Applied Polymer Science, 93, 911-919 (2004). DOI: 10.1002/app.20533

[10] Schwach E., Avérous L.: Starch-based biodegradable blends: Morphology and interface properties. Polymer International, 53, 2115-2124 (2004).

DOI: $10.1002 /$ pi.1636
[11] Stepto R. F. T.: Understanding the processing of thermoplastic starch. Macromolecular Symposia, 245246, 571-577 (2006).

DOI: $10.1002 /$ masy. 200651382

[12] Tomasik P., Schilling C. H.: Chemical modification of starch. Advances in Carbohydrate Chemistry and Biochemistry, 59, 175-403 (2004). DOI: $10.1016 / \mathrm{S} 0065-2318(04) 59005-4$

[13] Ramesh M., Mitchell J. R., Harding S. E.: Amylose content of rice starch. Starch, 51, 311-313 (1999). DOI: 10.1002/(SICI)1521-379X(199909)51:8/9<311:: AID-STAR311>3.0.CO;2-E

[14] Wallace R. A., King J. L., Sanders G. P.: Biology- The science of life. Goodyear Publishing Company, California (1981).

[15] Stepto R. F. T.: The processing of starch as a thermoplastic. Macromolecular Symposia, 201, 203-212 (2003).

DOI: $\underline{10.1002 / \text { masy.200351123 }}$

[16] Primarini D., Ohta Y.: Some enzyme properties of raw starch digesting amylases from streptomyces sp. No. 4. Starch, 52, 28-32 (2000).

DOI: $10.1002 /($ SICI $) 1521-379 X(200001) 52: 1<28:$ : AID-STAR28>3.0.CO;2-J

[17] Choi E-J., Kim C-H., Park J-K.: Synthesis and characterization of starch- $g$-polycaprolactone copolymer. Macromolecules, 32, 7402-7408 (1999).

DOI: $\underline{10.1021 / \mathrm{ma} 981453 \mathrm{f}}$

[18] Griffin G. J. L.: Biodegradable synthetic resin sheet material containing starch and a fatty material. U.S. Patent: 4016117, USA (1977).

[19] Bikiaris D., Prinos J., Koutsopoulos K., Vouroutzis N., Pavlidou E., Frangis N., Panayiotou C.: LDPE/ plasticized starch blends containing PE-g-MA copolymer as compatibilizer. Polymer Degradation and Stability, 59, 287-291 (1998).

DOI: $\underline{10.1016 / \mathrm{S} 0141-3910(97) 00126-2}$

[20] Mani R., Bhattacharya M.: Properties of injection moulded blends of starch and modified biodegradable polyesters. European Polymer Journal, 37, 515-526 (2001). DOI: $\underline{10.1016 / \mathrm{S} 0014-3057(00) 00155-5}$

[21] Ratto J. A., Stenhouse P. J., Auerbach M., Mitchell J., Farrell R.: Processing, performance and biodegradability of a thermoplastic aliphatic polyester/starch system. Polymer, 40, 6777-6788 (1999). DOI: $\underline{10.1016 / \mathrm{S} 0032-3861(99) 00014-2}$

[22] Jun C. L.: Reactive blending of biodegradable polymers: PLA and starch. Journal of Polymers and the Environment, 8, 33-37 (2000). DOI: 10.1023/A:1010172112118

[23] Wang N., Yu J. G., Chang P. R., Ma X.: Influence of formamide and water on the properties of thermoplastic starch/poly(lactic acid) blends. Carbohydrate Polymers, 71, 109-118 (2008). DOI: $10.1016 /$ j.carbpol.2007.05.025 
[24] Wang N., Yu J. G., Ma X. F.: Preparation and characterization of compatible thermoplastic dry starch/ poly(lactic acid). Polymer Composites, 29, 551-559 (2008).

DOI: $10.1002 /$ pc.20399

[25] Park J. W., Im S. S., Kim S. H., Kim Y. H.: Biodegradable polymer blends of poly(L-lactic acid) and gelatinized starch. Polymer Engineer and Science, 40, 2539-2550 (2000). DOI: $10.1002 /$ pen.11384

[26] Martin O., Avérous L.: Poly(lactic acid): Plasticization and properties of biodegradable multiphase systems. Polymer, 42, 6209-6219 (2001).

DOI: $10.1016 / \mathrm{S} 0032-3861(01) 00086-6$

[27] Scott G., Gilead D.: Degradable polymers: Principles and applications. Chapman and Hall, London (1995).

[28] Pitt C. G., Gratzl M. M., Jeffcoat A. R., Zweidinger R. A., Schindler A.: Sustained drug delivery systems II: Factors affecting release rates from poly( $\varepsilon$-caprolactone) and related biodegradable polyesters. Journal of Pharmaceutical Sciences, 68, 1534-1538 (1979). DOI: $10.1002 / j p s .2600681219$

[29] Li S. M., Espartero J. L., Foch P., Vert M.: Structural characterization and hydrolytic degradation of $\mathrm{Zn}$ metal initiated copolymer of L-lactide and $\varepsilon$-caprolactone. Journal of Biomaterials Science, Polymer Edition, 8, 165-187 (1997). DOI: $10.1163 / 156856296 X 00237$

[30] Vikman M., Hulleman S. H. D., van der Zee M., Myllärinen P., Feil H.: Morphology and enzymatic degradation of thermoplastic starch-polycaprolactone blends. Journal Applied Polymer Science, 74, 25942604 (1999).

DOI: $10.1002 /($ SICI $) 1097-4628(19991209) 74: 11$ $\leq 2594::$ AID-APP5>3.0.CO;2-R

[31] Dubois P., Krishnan M., Narayan R.: Aliphatic polyester grafted starch-like polysaccharides by ring-opening polymerization. Polymer, 40, 3091-3100 (1999). DOI: 10.1016/S0032-3861(98)00110-4

[32] Averous L., Moro L., Dole P., Fringant C.: Properties of thermoplastic blends: Starch-polycaprolactone. Polymer, 41, 4157-4167 (2000). DOI: $10.1016 / \mathrm{S} 0032-3861(99) 00636-9$

[33] Singh R. P., Pandey J. K., Rutot D., Degée Ph., Dubois Ph.: Biodegradation of poly( $\varepsilon$-caprolactone)/ starch blends and composites in composting and culture environments: The effect of compatibilization on the inherent biodegradability of the host polymer. Carbohydrate Research, 338, 1759-1769 (2003). DOI: $\underline{10.1016 / \mathrm{S} 0008-6215(03) 00236-2}$

[34] di Franco C. R., Cyras V. P., Busalmen J. P., Ruseckaite R. A., Vázquez A.: Degradation of polycaprolactone/starch blends and composites with sisal fibre. Polymer Degradation and Stability, 86, 95-103 (2004).

DOI: $10.1016 /$ j.polymdegradstab.2004.02.009
[35] Vertuccio L., Gorrasi G., Sorrentino A., Vittoria V.: Nano clay reinforced PCL/starch blends obtained by high energy ball milling. Carbohydrate Polymers, 75, 172-179 (2009).

DOI: $10.1016 /$ j.carbpol.2008.07.020

[36] Chiellini E., Corti A., D'Antone S., Solaro R.: Biodegradation of poly(vinyl alcohol) based materials. Progress in Polymer Science, 28, 963-1014 (2003).

DOI: $10.1016 / \mathrm{S} 0079-6700(02) 00149-1$

[37] Tudorachi N., Cascaval C. N., Rusu M., Pruteanu M.: Testing of polyvinyl alcohol and starch mixtures as biodegradable polymeric materials. Polymer Testing, 19, 785-799 (2000). DOI: $\underline{10.1016 / \mathrm{S} 0142-9418(99) 00049-5}$

[38] Lawton J. W.: Effect of starch type on the properties of starch containing films. Carbohydrate Polymers, 29, 203-208 (1996). DOI: $10.1016 / 0144-8617(96) 00028-8$

[39] Haschke H., Tomka I., Keilbach A.: Systematic investigations on the biological degradability of packing material III. New polyvinylalcohol-starch-acetal films (in German). Monatshefte für Chemie/ Chemical Monthly, 12, 487-507 (1998). DOI: $\underline{10.1007 / P L 00000106}$

[40] Ke T., Sun X. S.: Starch, poly(lactic acid), and poly(vinyl alcohol) blends. Journal of Polymers and the Environment, 11, 7-14 (2003). DOI: $10.1023 / \mathrm{A}: 1023875227450$

[41] Zhai M. L., Zhao L., Yoshii F., Kume T.: Study on antibacterial starch/chitosan blend film formed under the action of irradiation. Carbohydrate Polymer, 57, 83-88 (2004).

DOI: $10.1016 /$ j.carbpol.2004.04.003

[42] Bourtoom T., Chinnan M. S.: Preparation and properties of rice starch-chitosan blend biodegradable film. LWT-Food Science and Technology, 41, 1633-1641 (2008). DOI: $10.1016 /$ j.lwt.2007.10.014

[43] Psomiadou E., Arvanitoyannis I., Yamamoto N.: Edible films made from natural resources; Microcrystalline cellulose (MCC), methylcellulose (MC) and corn starch and polyols-Part 2. Carbohydrate Polymer, 31, 193-204 (1996). DOI: $\underline{10.1016 / S 0144-8617(96) 00077-X}$

[44] Suvorova A. I., Tyukova I. S., Trufanova E. I.: Biodegradable starch-based polymeric materials. Russian Chemical Reviews, 69, 451-459 (2000). DOI: 10.1070/RC2000v069n05ABEH000505

[45] Cao X., Chen Y., Chang P. R., Muir A. D., Falk G.: Starch-based nanocomposites reinforced with flax cellulose nanocrystals. Express Polymer Letters, 2, 502510 (2008). DOI: $10.3144 /$ expresspolymlett.2008.60

[46] Bao J. S., Xing J., Phillips D. L., Corke H.: Physical properties of octenyl succinic anhydride modified rice, wheat, and potato starches. Journal of Agricultural and Food Chemistry, 51, 2283-2287 (2003). DOI: $10.1021 / \mathrm{jf020371 \textrm {u }}$ 
[47] Kiatkamjornwong S., Mongkolsawat K., Sonsuk M.: Synthesis and property characterization of cassava starch grafted poly[acrylamide-co-(maleic acid)] superabsorbent via $\gamma$-irradiation. Polymer, 43, 39153924 (2002).

DOI: $10.1016 / \mathrm{S} 0032-3861(02) 00224-0$

[48] Chen L., Qiu X. Y., Xie Z. G., Hong Z. K., Sun J. R., Chen X. S., Jing X. B.: Poly(L-lactide)/starch blends compatibilized with poly(L-lactide)-g-starch copolymer. Carbohydrate Polymers, 65, 75-80 (2006).

DOI: 10.1016/j.carbpol.2005.12.029

[49] Choi E-J., Kim C-H., Park J-K.: Structure-property relationship in $\mathrm{PCL} /$ starch blend compatibilized with starch-g-PCL copolymer. Journal of Polymer Science Part B: Polymer Physics, 37, 2430-2438 (1999).

DOI: $\underline{10.1002 /(\text { SICI }) 1099-0488(19990901) 37: 17<}$ 2430::AID-POLB14>3.0.CO;2-4

[50] Chen L., Xie Z. G., Zhuang X. L., Chen X. S., Jing X. B.: Controlled release of urea encapsulated by starchg-poly(L-lactide). Carbohydrate Polymers, 72, 342348 (2008).

DOI: 10.1016/j.carbpol.2007.09.003

[51] Xu Q., Kennedy J. F., Liu L. J.: An ionic liquid as reaction media in the ring opening graft polymerization of $\varepsilon$-caprolactone onto starch granules. Carbohydrate Polymers, 72, 113-121 (2008).

DOI: 10.1016/j.carbpol.2007.07.031

[52] Fanta G. F., Burr R. C., Doane W. M., Russell C. R.: Graft polymerization of vinyl acetate onto starch. Saponification to starch-g-poly(vinyl alcohol). Journal of Applied Polymer Science, 23, 229-240 (1979).

DOI: $10.1002 / a p p .1979 .070230121$

[53] Simi C. K., Abraham T. E.: Hydrophobic grafted and crosslinked starch nanoparticles for drug delivery. Bioprocess and Biosystems Engineering, 30, 173-180 (2007).

DOI: $10.1007 / \mathrm{s} 00449-007-0112-5$

[54] Samaha S. H., Nasr H. E., Hebeish A.: Synthesis and characterization of starch-poly(vinyl acetate) graft copolymer and their saponified form. Journal of Polymer Research, 12, 343-353 (2005).

DOI: $10.1007 / \mathrm{s} 10965-004-7937-2$

[55] Xiao C. M., Yang M. L.: Controlled preparation of physical cross-linked starch-g-PVA hydrogel. Carbohydrate Polymer, 64, 37-40 (2006).

DOI: $10.1016 /$ j.carbpol.2005.10.020

[56] Zhu Z. F., Zhuo R. X.: Slow release behavior of starch-g-poly(vinyl alcohol) matrix for 2,4,5trichlorophenoxyacetic acid herbicide. European Polymer Journal, 37, 1913-1919 (2001).

DOI: $\underline{10.1016 / \mathrm{S} 0014-3057(01) 00055-6}$

[57] Grote C., Lazik W., Heinze T.: Tartaric acid starch ether: A novel biopolymer-based polyelectrolyte. Macromolecular Rapid Communications, 24, 927931 (2003).

DOI: $10.1002 /$ marc. 200300042

[58] Xiao C. M., Ye J.: Preparation of the carboxylic derivates of starch with maleic anhydride. Chinese Journal of Applied Chemistry, 22, 643-646 (2005).
[59] Xiao C. M., Fang F.: Ionic self-assembly and characterization of a polysaccharide-based polyelectrolyte complex of maleic starch half-ester acid with chitosan. Journal of Applied Polymer Science, 112, 2255-2260 (2009).

DOI: 10.1002/app.29763

[60] Zhao R. X., Torley P., Halley P. J.: Emerging biodegradable materials: Starch- and protein-based bio-nanocomposites. Journal of Material Science, 43, 3058-3071 (2008).

DOI: $\underline{10.1007 / \mathrm{s} 10853-007-2434-8}$

[61] Ozdemir M., Floros J. D.: Active food packaging technologies. Critical Reviews in Food Science and Nutrition, 44, 185-193 (2004). DOI: $\underline{10.1080 / 10408690490441578}$

[62] Avella M., de Vlieger J. J., Errico M. E., Fischer S., Vacca P., Volpe M. G.: Biodegradable starch/clay nanocomposite films for food packaging applications. Food Chemistry, 93, 467-474 (2005).

DOI: $\underline{10.1016 / \text { j.foodchem.2004.10.024 }}$

[63] The D. P., Debeaufort F., Voilley A., Luu D.: Biopolymer interactions affect the functional properties of edible films based on agar, cassava starch and arabinoxylan blends. Journal of Food Engineering, 90, 548-558 (2009).

DOI: 10.1016/j.jfoodeng.2008.07.023

[64] Flores S., Haedo A. S., Campos C., Gerschenson L.: Antimicrobial performance of potassium sorbate supported in tapioca starch edible films. European Food Research Technology, 225, 375-384 (2007). DOI: 10.1007/s00217-006-0427-5

[65] Siracusa V., Rocculi P., Romani S., Rosa M. D.: Biodegradable polymers for food packaging: A review. Trends in Food Science and Technology, 19, 634-643 (2008).

DOI: $10.1016 /$ j.tifs.2008.07.003

[66] Dilara P. A., Briassoulis D.: Degradation and stabilization of low-density polyethylene films used as greenhouse covering materials. Journal of Agricultural Engineering Research, 76, 309-321 (2000). DOI: 10.1006/jaer.1999.0513

[67] Bohlmann G., Toki G.: Chemical economics handbook. SRI International, Menlo Park (2004).

[68] Dave A. M., Mehta M. H., Aminabhavi T. M., Kulkarni A. R., Soppimath K. S.: A review on controlled release of nitrogen fertilizers through polymeric membrane devices. Polymer-Plastics Technology and Engineering, 38, 675-711 (1999). DOI: $10.1080 / 03602559909351607$

[69] Guo M., Liu M., Zhan F., Wu L.: Preparation and properties of a slow-release membrane-encapsulated urea fertilizer with superabsorbent and moisture preservation. Industrial and Engineering Chemistry Research, 44, 4206-4211 (2005). DOI: $\underline{10.1021 / \mathrm{ie} 0489406}$ 
[70] Kumbar S. G., Kulkarni A. R., Dave A. M., Aminabha T. M.: Encapsulation efficiency and release kinetics of solid and liquid pesticides through urea formaldehyde crosslinked starch, guar gum, and starch + guar gum matrices. Journal of Applied Polymer Science, 82, 2863-2866 (2001).

DOI: $10.1002 / \mathrm{app} .2141$

[71] Malinconico M., Immirzi B., Massenti S., La Mantia F. P., Mormile P., Petti L.: Blends of polyvinylalcohol and functionalised polycaprolactone. A study on the melt extrusion and post-cure of films suitable for protected cultivation. Journal of Materials Science, 37, 4973-4978 (2002).

DOI: 10.1023/A:1021058810774

[72] Scott G.: 'Green' polymers. Polymer Degradation and Stability, 68, 1-7 (2000). DOI: $10.1016 / \mathrm{S} 0141-3910(99) 00182-2$

[73] Scarascia-Mugnozza G., Schettini E., Vox G., Malinconico M., Immirzi B., Pagliara S.: Mechanical properties decay and morphological behaviour of biodegradable films for agricultural mulching in real scale experiment. Polymer Degradation and Stability, 91, 2801-2808 (2006).

DOI: $10.1016 /$ j.polymdegradstab.2006.02.017

[74] Wang Y-Z., Yang K-K., Wang X-L., Zhou Q., Zheng C-Y., Chen Z-F.: Agricultural application and environmental degradation of photo-biodegradable polyethylene mulching films. Journal of Polymers and the Environment, 12, 7-10 (2004).

DOI: 10.1023/B:JOOE.0000003122.71316.8e

[75] Yew S. P., Tang H. Y., Sudesh K.: Photocatalytic activity and biodegradation of polyhydroxybutyrate films containing titanium dioxide. Polymer Degradation and Stability, 91, 1800-1807 (2006). DOI: 10.1016/j.polymdegradstab.2005.11.011

[76] Marques A. P., Reis R. L., Hunt J. A.: The biocompatibility of novel starch-based polymers and composites: In vitro studies. Biomaterials, 23, 1471-1478 (2002). DOI: 10.1016/S0142-9612(01)00272-1

[77] Mendes S. C., Reis R. L., Bovell Y. P., Cunha A. M., van Blitterswijk C. A., de Bruijn J. D.: Biocompatibility testing of novel starch-based materials with potential application in orthopaedic surgery: A preliminary study. Biomaterials, 22, 2057-2064 (2001). DOI: 10.1016/S0142-9612(00)00395-1

[78] Azevedo H. S., Gama F. M., Reis R. L.: In vitro assessment of the enzymatic degradation of several starch based biomaterials. Biomacromolecules, 4, 1703-1712 (2003). DOI: $\underline{10.1021 / \mathrm{bm} 0300397}$
[79] Defaye J., Wong E.: Structural studies of gum arabic, the exudate polysaccharide from acacia senegal. Carbohydrate Research, 150, 221-231 (1986). DOI: $10.1016 / 0008-6215(86) 80018-0$

[80] Reddy S. M., Sinha V. R., Reddy D. S.: Novel oral colon-specific drug delivery systems for pharmacotherapy of peptides and nonpeptide drugs. Drugs of Today, 35, 537-580 (1999).

[81] Sinha V. R., Kumria R.: Polysaccharides in colon-specific drug delivery. International Journal of Pharmaceutics, 224, 19-38 (2001). DOI: $\underline{10.1016 / \mathrm{S} 0378-5173(01) 00720-7}$

[82] Boesel L. F., Mano J. F., Reis R. L.: Optimization of the formulation and mechanical properties of starch based partially degradable bone cements. Journal of Materials Science: Materials in Medicine, 15, 73-83 (2004). DOI: 10.1023/B:JMSM.0000010100.07715.eb

[83] Gomes M. E., Sikavitsas V. I., Behravesh E., Reis R. L., Mikos A. G.: Effect of flow perfusion on the osteogenic differentiation of bone marrow stromal cells cultured on starch-based three-dimensional scaffolds. Journal of Biomedical Materials Research Part A, 67, 87-95 (2003).

DOI: $\underline{10.1002 / \mathrm{jbm} \cdot \mathrm{a} \cdot 10075}$

[84] Balmayor E. R., Tuzlakoglu K., Marques A. P., Azevedo H. S., Reis R. L.: A novel enzymaticallymediated drug delivery carrier for bone tissue engineering applications: Combining biodegradable starchbased microparticles and differentiation agents. Journal of Material Science: Materials in Medicine, 19, 1617-1623 (2008).

DOI: $10.1007 / \mathrm{s} 10856-008-3378-5$

[85] Reis A. V., Guilherme M. R., Moia T. A., Mattoso L. H. C., Muniz E. C., Tambourgi E. B.: Synthesis and characterization of a starch-modified hydrogel as potential carrier for drug delivery system. Journal of Polymer Science Part A: Polymer Chemistry, 46, 2567-2574 (2008).

DOI: $10.1002 /$ pola.22588

[86] Peppas N. A., Bures P., Leobandung W., Ichikawa H.: Hydrogels in pharmaceutical formulations. European Journal of Pharmaceutics and Biopharmaceutics, 50, 27-46 (2000). DOI: $10.1016 / \mathrm{S} 0939-6411(00) 00090-4$

[87] Gao Y. K., Xiao C. M.: Preparation and characterization of starch-g-PVA/nano-hydroxyapatite complex hydrogel. Journal of Wuhan University of Technology-Materials Science Edition, 20, 58-59 (2005). 